Editorial

\title{
Journal of Young Pharmacists: Now published with Elsevier
}

The year 2013 is another milestone for Journal of Young Pharmacist (JYP) as it is entering to 5th year. It is known as one of the peerreviewed pharmaceutical journal and I am pleased to present you this issue being published by Elsevier (World's top publisher). Over the years the journal is indexed with Caspur, Chemical Abstracts, CNKI, DOAJ, EBSCO Publishing's Electronic Databases, Expanded Academic ASAP, Genamics JournalSeek, Global Health, Google Scholar, Health \& Wellness Research Center, Health Reference Center Academic, Hinari, Index Copernicus, Indian Science Abstracts, Open J-Gate, Primo Central, ProQuest, PubMed, Pubmed Central, SCImago Journal Ranking, SCOLOAR, SCOPUS, SIIC databases, Summon by Serial Solutions and Ulrich's International Periodical Directory. The new issue content for volume 5 is available "http://www.jyoungpharm.org/" and four years archive is available with previous website [www.jyoungpharm.in] as well as in "Science Direct".

\section{Editorial policy}

As JYP is moving ahead with Elsevier widening its global visibility, we have few changes in our editorial policies. Manuscripts being submitted to JYP will be preferred in IMRAD style and its mandatory to provide contributors details and author have to declare the conflict of interest. The clinical and pre-clinical experiment should be prepared accordance to "CONSORT" and "ARIVE" guidelines respectively. The manuscripts which are describing clinical findings have to provide "CONSORT" flow chart for easy understanding.

\section{Biomedical ethics}

The submitted manuscript should be satisfying the ethical regulation of author's mothers land and the guidelines which author flowed should be mentioned in the manuscript. If necessary, editor may request to submit the scanned copy of the ethical clearance letter.

\section{Sections of JYP}

Apart from regular research and review articles, and short communication, JYP is introducing mini reviews, and conference report and correspondence sections. The new section is to encourage the student and young researchers. The word limit for mini review, research letter, conference report and correspondence will be around $>2000,>800,>2000$ and $>200$ words respectively. The correspondence will be submitted within one month after date of online publication of any research work and case reports in JYP.
JYP also includes new section named "Clinical Case Reports" to publish case reports. In past experience we published some of the case reports in letters to editor section, and this section is not appropriate for publishing the case reports. Hence, the editorial term adding new title named "Clinical Case Reports".

To encourage clinical pharmacist and help them to available their data globally in scientific platform, we are welcoming them to submit their clinical drug safety data, pharmacovigilance data in research paper section or in letters to editors section.

\section{Cutting edge research}

Articles covering different subjects within the journal scope are being invited. Articles with highly scientific relevant will be given more preference. Preliminary findings will not be encouraged; such findings can be submitted as letter to editor or short communications. Review articles are also welcome from authors having enormous expertise in area of review.

\section{How do we handle papers}

Author submitted manuscript are checked by journal manager, and if they conform to the journal style, image quality and table format are assigned to the editor-in-chief. I will check the content, originality of the work and ethical issues involved. If the manuscript has any ethical issue, lacking originality and out of our scope that will be rejected. All submitted manuscripts will be checked for plagiarism using iThenticate. Articles reporting plagiarized content will not be processed for peer review process. If manuscript is too lengthy and cross the prescribed word limit that will be send back to author for technical modification otherwise the manuscript will be send to panel of four/five reviewers. Based on reviewers comments further action will be taken on it.

\section{Article processing charges}

Due to increasing cost of publishing, JYP will have pre-press charges to cover the production cost with the publisher. Indian authors are required to pay a sum of 3000 INR (Pre-Press Charges) + 500 INR (Editor Charges) and foreign and Overseas Indian authors are required to pay 200 USD (Pre-Press Charges) + 50 USD (Editor Charges) upon acceptance. InPharm association members may request that the editorial office waiver of 1000 INR. The above charges are applicable to accepted articles only. JYP will not have any charges for submission or peer review of the submitted manuscripts. 


\section{Call for editorial board members}

We are seeking active members to support or act as a mentor in the growth of JYP. Editorial board members will have to screen submitted papers and help us continue to meet our mission; we are looking to add new members to our Editorial Board to serve initial three-year terms.

Members of our board take a posture of being supportive and nurturing to authors who submit papers to the journal. Instead of making our mark by citing how many papers we reject, we want to be known for helping authors become better writers and researchers. To this end, our reviewers work with the JYP editorial leadership team as part of an editorial community which unconditionally accepts all authors who submit their papers to the journal. In turn, we ask these authors to participate in the editorial process of writing and re-writing. In this approach, reviewers and editors become mentors to the authors and as a team we work collaboratively to produce the best papers and journal possible. As an Edito- rial Board Member, you will be expected to perform the following responsibilities:

- Review 2-3 new papers per quarter.

- Review revised manuscripts.

- Produce supportive and useful reviews.

- Participate in internal quality improvement activities (e.g., answer surveys, review new forms and procedures, provide feedback).

- Communicate with editors in a timely and professional manner.

S. Parasuraman Department of Pharmacology, Jawaharlal Institute of Post Graduate Medical Education and Research (JIPMER), Puducherry 6055 006, India E-mail address: parasuphd@gmail.com

Available online $\mathrm{xxx}$ 